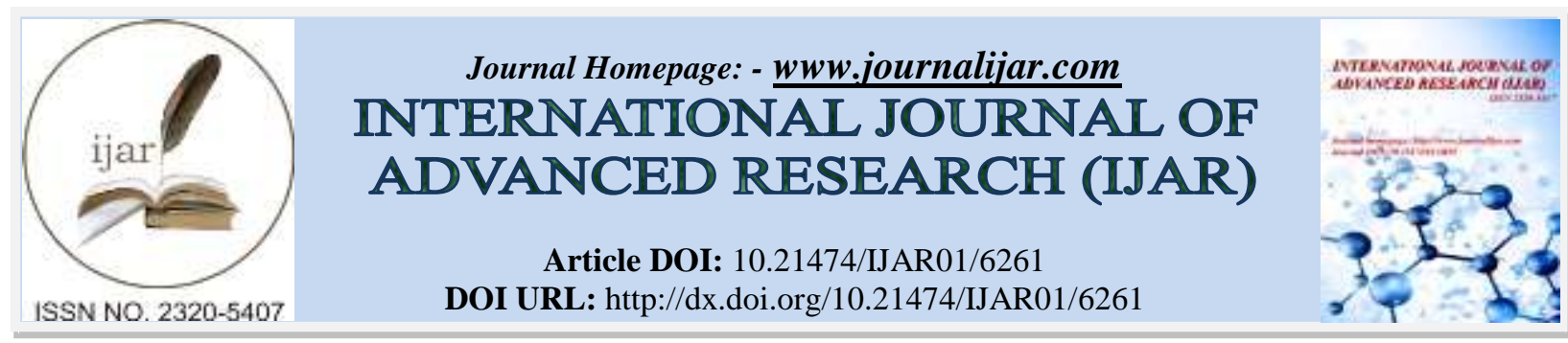

RESEARCH ARTICLE

\title{
CORRELATION BETWEEN MICROALBUMINURIA AND HBA1C AMONG TYPE2 DIABETIC PATIENTS IN JAMMU, J AND K STATE, INDIA.
}

Dr. Bawana Raina ${ }^{1}$, Dr. Puneeta Gupta ${ }^{2}$, Dr. Nawaf Khurshid Sheikh ${ }^{3}$ and Dr. Kapil Gupta ${ }^{4}$.

1. Associate Professor, Deptt of Pathology, Acharya Shri Chander College of Medical Sciences.

2. Professor of Medicine, Acharya Shri Chander College of Medical Sciences.

3. Post graduate student, Deptt of Pathology, Acharya Shri Chander College of Medical Sciences.

4. Post graduate student, Deptt of Medicine, Acharya Shri Chander College of Medical Sciences.

\section{Manuscript Info}

Manuscript History

Received: 09 November 2017

Final Accepted: 11 December 2017

Published: January 2018

Key words:-

Microalbuminuria, Type 2 Diabetes, Nephropathy, HbA1C

\section{Abstract}

It has been noted that $\mathrm{HbA1C}$ levels are higher in diabetic patients, who develop micro- and macroalbuminuria. There is strong evidence that poor blood glucose control contributes to the development of albuminuria. Although the exact cause of this diabetic nephropathy is not clearly known but one of the reasons, considered to be a high risk factor, is hyperglycemia. Diabetic nephropathy has been known to lead to chronic kidney disease world wide, which in turn is responsible for $30-40 \%$ end-stage renal disease (ESRD). The present study is based on 110 diabetics $(70$ males i.e. $63.6 \%$ and 40 females i.e. $36.3 \%$ ), selected from patients attending both the outpatient department and those admitted, during the period from January to June 2017, in the Department of Medicine ASCOMS and Hospital, Sidhra, Jammu. The mean duration of diabetes was $8.70 \pm 5.4$ years. The mean $\mathrm{HbA1C}$ was $7.91 \pm 0.95$ and mean microalbumin was $92.81 \pm 65.4 \mathrm{mg} /$ day. Our study revealed that out of 110 diabetic patients $25(22.72 \%)$ had $\mathrm{HbAlC} \leq 7 \%$ and $85(77.27 \%)$ had $\mathrm{HbA1C} \geq 7 \%$.Microalbuminuria was found in 65 (59.0\%) patients out of which $5(4.5 \%)$ patients had $\mathrm{HbAlC} \leq 7 \%$ and $60(54.5 \%)$ had $\mathrm{HbAlC} \geq 7 \%$, rest were normoalbuminuric. Patients having uncontrolled glycemic status with $\mathrm{HbA1C} \geq 7 \%$ showed positive correlation with microalbuminuria $>$ than $30 \mathrm{mg} /$ day and this was confirmed by Pearsons Correlation Coefficient of $r=0.818, p$ value $=0.001$ and Chi Square Test. In addition Pearsons Correlation Analysis also showed statistically significant correlation of microalbuminuria with duration of diabetes, $r=0.622$ and $\mathrm{p}<0.0001$.

Copy Right, IJAR, 2018,. All rights reserved.

\section{Introduction:-}

Diabetes Mellitus is an important metabolic disorder and is characterized by variable degrees of insulin resistance, impaired insulin secretion \& increased glucose levels associated with important chronic changes in the patients, termed as microvascular and macrovascular complications, accounting for increased disability and mortality. ${ }^{1}$ Now, as prevalence of DM is projected to increase from present 415 million patients in $2016^{2}$ to 642 million in 2040( $90 \%$ of these people will have Type 2 Diabetes),one of the greatest challenges encountered is, how to prevent the long term complications of DM in clinical practice. 
Microalbuminuria is defined as urinary albumin excretion rate of $20-200 \mu \mathrm{g} / \mathrm{min}$ or urinary protein excretion rate of 30-300 mg/day. ${ }^{3}$ Microalbuminuria (MAU) represents the simplest and most sensitive prognostic factor to evaluate the risk of overt nephropathy in diabetes, as it represents the first stage of progressive diabetic renal disease. Diabetic nephropathy has been defined as clinical syndrome, characterized by persistent albuminuria ( $>300 \mathrm{mg} / \mathrm{d}$ or $>200 \mu \mathrm{g} / \mathrm{min}$ ), that is confirmed on at least 2 occasions 3-6 months apart, progressive decline in the glomerular filtration rate (GFR) and elevated arterial blood pressure ${ }^{4}$.

Currently, diabetic nephropathy is the leading cause of chronic kidney disease and is responsible for 30-40\% of all the end-stage renal disease (ESRD). It is also one of the most significant long-term complications in terms of morbidity and mortality for individual patients with diabetes ${ }^{5}$. The data available from United States shows that, the prevalence of diabetic kidney disease increased directly in proportion to the prevalence of diabetes mellitus from the year 1988 to $2008 .^{5}$

In India similar studies have been conducted by Chowta et al. (2010) ${ }^{6}$ from Mangalore, Sanjeev Kumar et al. (2014) ${ }^{7}$, Tandon et al. (2015) ${ }^{8}$ from Meerut, and Muraliswaran et al. (2016) ${ }^{9}$, from Puducherry. As far as the authors are aware, the present study is the first from Jammu and Kashmir State.

\section{Materials and Methods:-}

A total of 110 diabetes mellitus Type 2 patients (70 males, $63.6 \%$ and 40 females, $36.3 \%$ ), with age ranging from 40 to 70 years (Mean age 50.57), who either attended the outpatient Department or were admitted in the Department of Medicine ASCOMS and Hospital, Sidhra, Jammu, during the period from January to June 2017, were selected for the present study. The written and informed consent was taken from all tese patients as per the prevalent norms and an Institutional Ethical Committee clearance was also obtained.

Subjects, diagnosed and confirmed by specialists, as suffering from Type 2 Diabetes Mellitus (DM), were included in the present study. The diagnosis of Diabetes Melitus was based on the following Criteria. ${ }^{10}$

Fasting plasma glucose $(\mathrm{FPG}) \geq 126 \mathrm{mg} / \mathrm{dL}(7.0 \mathrm{mmol} / \mathrm{L})$. Fasting is defined as no caloric intake for at least $8 \mathrm{~h} \mathrm{or}$ $12 \mathrm{~h}$. Post prandial $\geq 200 \mathrm{mg} / \mathrm{dL}(11.1 \mathrm{mmol} / \mathrm{L})$ during an oral glucose tolerance test or $\mathrm{HbA} 1 \mathrm{C} \geq 7 \%$.

Parameters taken as inclusion criteria are as follows: age of onset $>40$ years of age; Serum Creatinine $<1.5 \mathrm{mg} / \mathrm{dl}$; serum triglyceride $<400 \mathrm{mg} / \mathrm{dl}$; negative urine culture.

Patients with systemic disease like, Hypertension, Ischemic heart disease, Valvular heart disease, Congestive cardiac failure, hemoglobinopathies, and severe anemia were excluded from the study.

Venous blood samples after fasting were taken for plasma glucose (Glucose-Oxidase Peroxidase Method). Samples for $\mathrm{HbA1C}$ were taken in EDTA containers (Turbidimetric Inhibition Immunoassay). All urine samples were tested for glucose and albumin by reagent strip test. Albumin negatives were further tested quantitatively for microalbumin by Immune Turbidimetric Method. HbA1C levels $\leq 7$ and Microalbumin levels $\leq 30 \mathrm{mg} /$ day were considered to be normal. The subjects were divided into two groups according to glycemic control, based on their levels of plasma glucose, both in fasting condition and two hours after ingestion of $75 \mathrm{~g}$ glucose, and glycated hemoglobin as per the following criteria:

\section{Group 1 (Type 2 Diabetes Mellitus patients with poor glycemic control):}

Fasting plasma glucose (FPG) > $126 \mathrm{mg} / \mathrm{dl}$,

2 hour post-prandial glucose $(\mathrm{PPG})>200 \mathrm{mg} / \mathrm{dl}$ after a $75 \mathrm{~g}$ glucose load,

Glycated hemoglobin (Hb A1C) of $\geq 7 \%$.

Group 2 (Type 2 Diabetes Mellitus patients with adequate glycemic control):

Fasting plasma glucose $(\mathrm{FPG})<110 \mathrm{mg} / \mathrm{dl}$,

2 hour post-prandial glucose $(\mathrm{PPG})<140 \mathrm{mg} / \mathrm{dl}$ after a $75 \mathrm{~g}$ glucose load,

Glycated hemoglobin (HbA1C) of $\leq 7 \%$. 
Data were analysed using SPSS version 18. Pearson Correlation Coefficient was calculated to find the linear relation between HbA1C and Microalbuminuria, and also between duration of diabetes and Microalbuminuria. Chi-square Test was also used to find relationship. $p$ value was taken as significant at $5 \%$ confidence level $(\mathrm{p}<0.05)$.

\section{Results:-}

Among 110 known diabetic patients, 63.6\% were males and 36.3\% females (Fig. 1). The mean duration of diabetes was $8.70 \pm 5.4$ years. The mean $\mathrm{HbA1C}$ was $7.91 \pm 0.95$ and mean microalbumin was $92.81 \pm 65.4 \mathrm{mg} / \mathrm{day}$. Our study revealed that out of 110 diabetic patients $25(22.7 \%)$ had $\mathrm{HbA} 1 \mathrm{C} \leq 7 \%$ and $85(77.2 \%)$ had $\mathrm{HbA} 1 \mathrm{C} \geq 7 \%$.

Microalbuminuria was found in $65(59.0 \%)$ patients out of which 5 (4.5\%) patients had $\mathrm{HbA} 1 \mathrm{C} \leq 7 \%$ and 60 (54.5\%) had $\mathrm{HbA1C} \geq 7 \%$. The remaining 45 patients were normoalbumurics, out of which, however, $20(18.1 \%)$ patients had $\mathrm{HbA} 1 \mathrm{C} \leq 7 \%$ and 25 (22.7\%) had $\mathrm{HbA} 1 \mathrm{C} \geq 7 \%$ (Tab. 1 ).

A positive correlation was found amongdiabetic patients with uncontrolled glycaemic status, with $\mathrm{HbA} 1 \mathrm{C} \geq 7 \%$ and microalbumin $>30 \mathrm{mg}$ /day and this was evidenced by Pearson's Correlation Co-efficient $(\mathrm{r}=0.818)$ and Chi-square test. $\mathrm{p}$ value of 0.001 i.e. less than $\mathrm{p}<0.05$ was considered statistically significant (Fig. 2).

Mean duration of diabetes in microalbuminuric patients was 11.5years while in normoalbuminuric patients it was 4.6years, which is statistically highly significant. Pearson Correlation Analysis showed statistically significant correlation of microalbuminaria with duration of diabetes i. e. $\mathrm{r}=0.622, \mathrm{p}=<0.0001$.

Correlation of duration of DM with albuminuria, $+\mathrm{P}$ value

\begin{tabular}{|c|c|c|c|}
\hline \multicolumn{4}{|c|}{ Correlation of durat with albuminuria $+\mathrm{P} v$} \\
\hline S.No. & $\begin{array}{l}\text { Duation of } \\
\text { DM }\end{array}$ & $\begin{array}{l}\text { No. of Patients } \\
\text { with } \\
\text { (albuminuria) }\end{array}$ & $\begin{array}{l}\text { No. of patients } \\
\text { normal } \\
\text { albuminuria }<30 \\
\text { mg/dl }\end{array}$ \\
\hline 1 & $1-5$ years & $5(4.5 \%)$ & $23(20.9 \%)$ \\
\hline 2 & $5-10$ years & $10(9.09 \%)$ & $20(18.1 \%)$ \\
\hline 3 & $10-15$ years & $30(27.2 \%)$ & $2(1.8 \%)$ \\
\hline 4 & $>15 y e a r s$ & $20(18.18 \%)$ & $0(0 \%)$ \\
\hline \multicolumn{4}{|c|}{ Correlation co-efficient between HBA1C + Microalbumin } \\
\hline $\begin{array}{l}\text { Microalbumi } \\
n\end{array}$ & $<30 \mathrm{mg} / \mathrm{l}$ & $>30 \mathrm{mg} / \mathrm{l}$ & \\
\hline HBA1C & $\begin{array}{l}\text { No. of } \\
\text { Patient }\end{array}$ & No of Patients & \\
\hline$<7 \%$ & $20(18.1)$ & $5(14.5 \%)$ & 25 \\
\hline$>7 \%$ & $25(22.7)$ & $60(54.5)$ & 85 \\
\hline & 45 & 65 & 110 \\
\hline
\end{tabular}

Tab 2:- Correlation of duration with albuminuria

\begin{tabular}{|l|l|l|l|}
\hline S.No. & Duation of DM & No. of Patients with (albuminuria) & $\begin{array}{l}\text { No. of patients normal } \\
\text { albuminuria }<30 \mathrm{mg} / \mathrm{dl}\end{array}$ \\
\hline 1 & $1-5$ years & $5(4.5 \%)$ & $23(20.9 \%)$ \\
\hline 2 & $5-10$ years & $10(9.09 \%)$ & $20(18.1 \%)$ \\
\hline 3 & $10-15$ years & $30(27.2 \%)$ & $2(1.8 \%)$ \\
\hline 4 & $>15$ years & $20(18.18 \%)$ & $0(0 \%)$ \\
\hline
\end{tabular}

Tab 1:- Correlation co-efficient between HBA1C + Microalbumin

\begin{tabular}{|l|l|l|l|}
\hline Microalbumin & $<30 \mathrm{mg} / \mathrm{l}$ & $>30 \mathrm{mg} / \mathrm{l}$ & \\
\hline HBA1C & No. of Patient & No of Patients & \\
\hline$<7 \%$ & $20(18.1)$ & $5(14.5 \%)$ & 25 \\
\hline
\end{tabular}




\begin{tabular}{|l|l|l|l|}
\hline$>7 \%$ & $25(22.7)$ & $60(54.5)$ & 85 \\
\hline & 45 & 65 & 110 \\
\hline
\end{tabular}

\section{Discussion:-}

According to a report of World Health Organisation (WHO), ${ }^{2}$ the number of people with diabetes has risen from 108 million to 422 million, and the global prevalence of diabetes among adults, over 18 years, has risen from $4.7 \%$ to $8.5 \%$ from the year 1980 to 2014. In addition it has been the major cause of blindness, kidney failure, heart attacks, strokes and lower limb amputations. India also has a vast population of diabetics, about 69 million, second largest after China; most of them being, illiterate and medically ill informed about this disease and are unaware about its serious implications and complications, adding to their woes. In many cases, it is often too late, as the patients are already victims of most of its complications, by the time the disease is diagnosed. This is evident from the findings of $\mathrm{WHO}$, that $46 \%$ of people with diabetes are undiagnosed globally.

The prevalence of microalbuminaria in Type 2 diabetes is variable and ranges from as low as $25 \%$ (Ghai et al. 1994) ${ }^{11}$ to as high as $84.21 \%$ (Kumaret al. 2014). ${ }^{7}$ In the present study, the prevalence of microalbuminaria in Jammu was $59 \%$, whereas, it has been reported to be $37 \%$ in Mangalore by Chowta et al. ${ }^{6}(2010), 43.5 \%$ in Meerut by Tandon et.al. ${ }^{8}$ (2015) and $48 \%$ in Poducherry by Muraliswaran et.al. ${ }^{9}$ (2016). It is worth while to note that while Kumar et.al ${ }^{7}$ in 2014 found it $84.21 \%$, but Tandon et.al ${ }^{8}$ one year later, in 2015 report it only $43.5 \%$ from the same region i. e. Meerut. How it got drastically reduced to almost one half in one year, although encouraging, is yet open to further investigation and needs confirmation.

The higher percentage of prevalence of microalbuminaria in the present report can have a number of reasons. According to Chowta et.al.(2010) ${ }^{6}$, one of the main causes is, " irregular treatment with poor glycemic control and also may be due to the "small sample size" in their study. The sample size in the above report and the present study is almost similar, being 100 and 110 respectively. However, we feel that, sample size does not play much role in this and agree with them in suggesting that, "the level of glycemic control seems to be the strongest factor influencing transition from normoalbuminuria to microalbuminuria." They further suggest that, "ethinical differences also play a role in giving a higher prevalence of microalbuminuria" with which the present authors agree.

Mean age of patients with diabetes in the present study was 50.57 years, which is similar to that, reported by Chowta et $a l^{6}$, Kanakmani et al. ${ }^{12}$ and Maskari et al. ${ }^{13}$ whereas, in the studies of Tandon et al. ${ }^{8}$ the patients belonged to a younger age group with mean age of 52.2 years. Generally, diabetic nephropathy affects both males and females equally. This was also confirmed by the present study.

The level of $\mathrm{HbA1C}$ has been widely accepted as an indicator of mean daily blood glucose concentration over the preceding 8-12 weeks. The glycated hemoglobin (HbA1C) assay is the most commonly used measure of chronic glycaemia, since its introduction more than 25 years ago. ${ }^{14} \mathrm{HbA} 1 \mathrm{C}$ levels equal to or less than $6.5 \%$ in diabetes, reflects good glycemic control and more than $7.5 \%$ will put patient at greater risk of developing disease related complications, including nepthropathy. ${ }^{15}$

The observation that, 60 patients, $54.5 \%$ showed microalbuminuria and had $\mathrm{HbA} 1 \mathrm{C} \geq 7 \%$ and only 25 patients, $22.7 \%$ were normoalbuminuric inspite of $\mathrm{HbAlC} \geq 7$, is due to the fact that the former had DM for more than seven years and in the latter, it was for less than seven years. Significant correlation was found in the present study between $\mathrm{HbA1C}$, microalbuminaria and duration of T2 DM. Baig et al ${ }^{16}$ have also shown significant correlation between long duration of T2 DM with high level of microalbumin.In addition the studies of Muraliswaran et al. ${ }^{9}$ and Gupta et al. ${ }^{17}$ lend support to the present study.

Out of a total 65 microalbuminaria patients, maximum30 patients (46.1\%) had DM for a duration of 10 to 15 years, whereas, 20 patients (30\%) had DM for a duration of more than 15 years, 10 patients (15.3\%) for 5 to 10 years and minimum 5 patiens $(7 \%)$ had DM for 1 to 5 years which is in conformity with the findings of Chowta etal ${ }^{6}$ and Acharya et al. ${ }^{18}$ In contrast Tandon $e t$ al. ${ }^{8}$ had maximum cases $(79.8 \%)$ with microalbuminaria, who had DM for a duration of 6 to 10 years .

In the present study, it is found that diabetics with poor glycemic control had higher microalbumin levels compared with those of diabetics with good glycemic control. This study also highlights that there is a significant correlation 
between microalbumin levels and HbA1C.Varghese et al. ${ }^{19}$ carried out study among type 2 diabetic people and found a positive correlation between microalbuminuria and $\mathrm{HbA} 1 \mathrm{C}$ but did not find any statistical difference between microalbuminuria and two sexes.

Impaired glycemic control is associated with significant elevations in urinary microalbumin levels. Furthermore, there is an increased urinary microalbumin level with increased duration of diabetes, which suggests that the detection of increased urinary microalbumin levels at the initial stage can avert, reduce the clinical and economic burden of diabetic complications in future. ${ }^{20}$

\section{Conclusion:-}

Screening for urine albumin among persons with diabetes is widely recommended for the detection and treatment of incipient diabetic nephropathy and affects the physician's implementation of therapy to slow progression of kidney disease. Despite widespread recommendations for screening of persons with diabetes for both glycemic control and urine albumin, there has not been a systematic assembly of the literature to assess the risk relation between tests assessing long-term glycemic control or tests assessing the presence of microalbuminuria with cardiovascular, peripheral vascular, renal, and neurological outcomes (all of which represent end-organ effects of long-term diabetes). Despite its devastating consequences, microalbuminuria is still a largely unrecognized risk factor, and a large proportion of individuals with diabetes are not regularly screened.

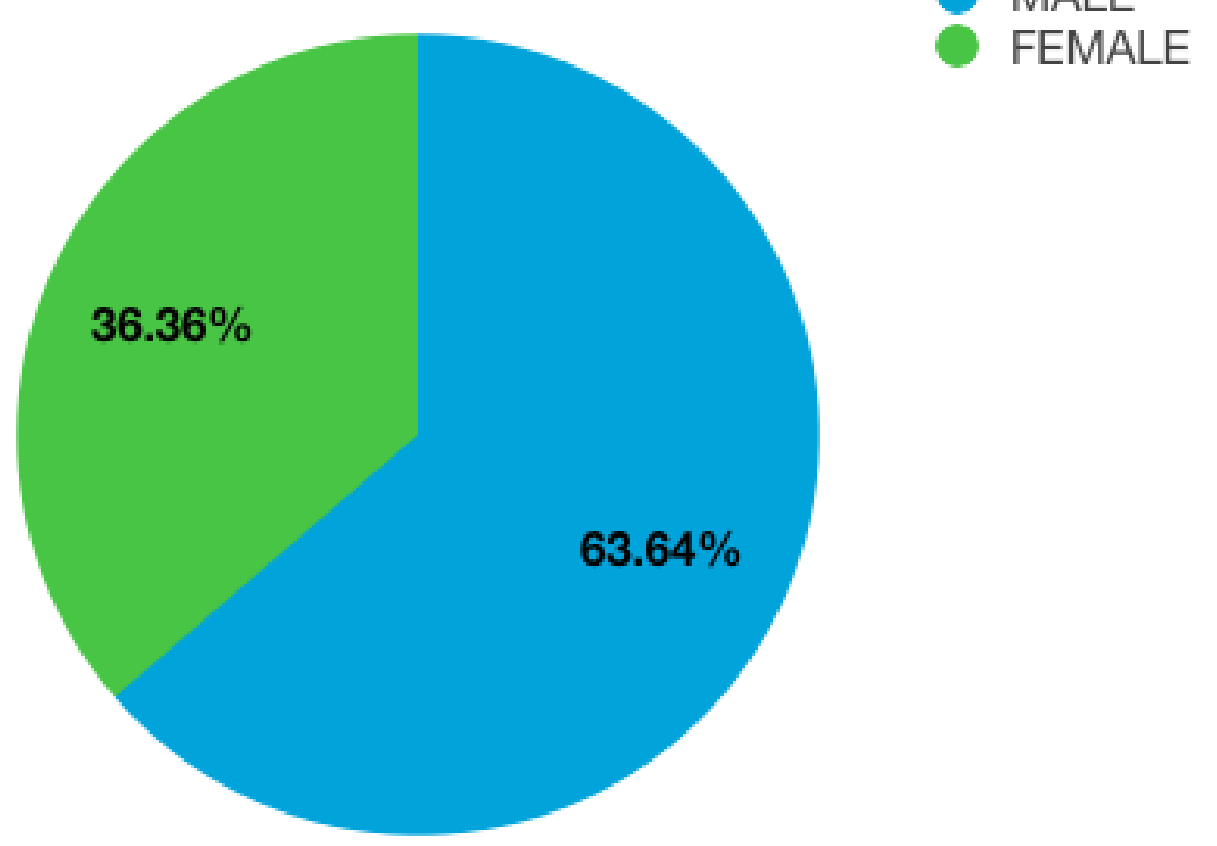

Fig 1:- Showing gender distribution. 


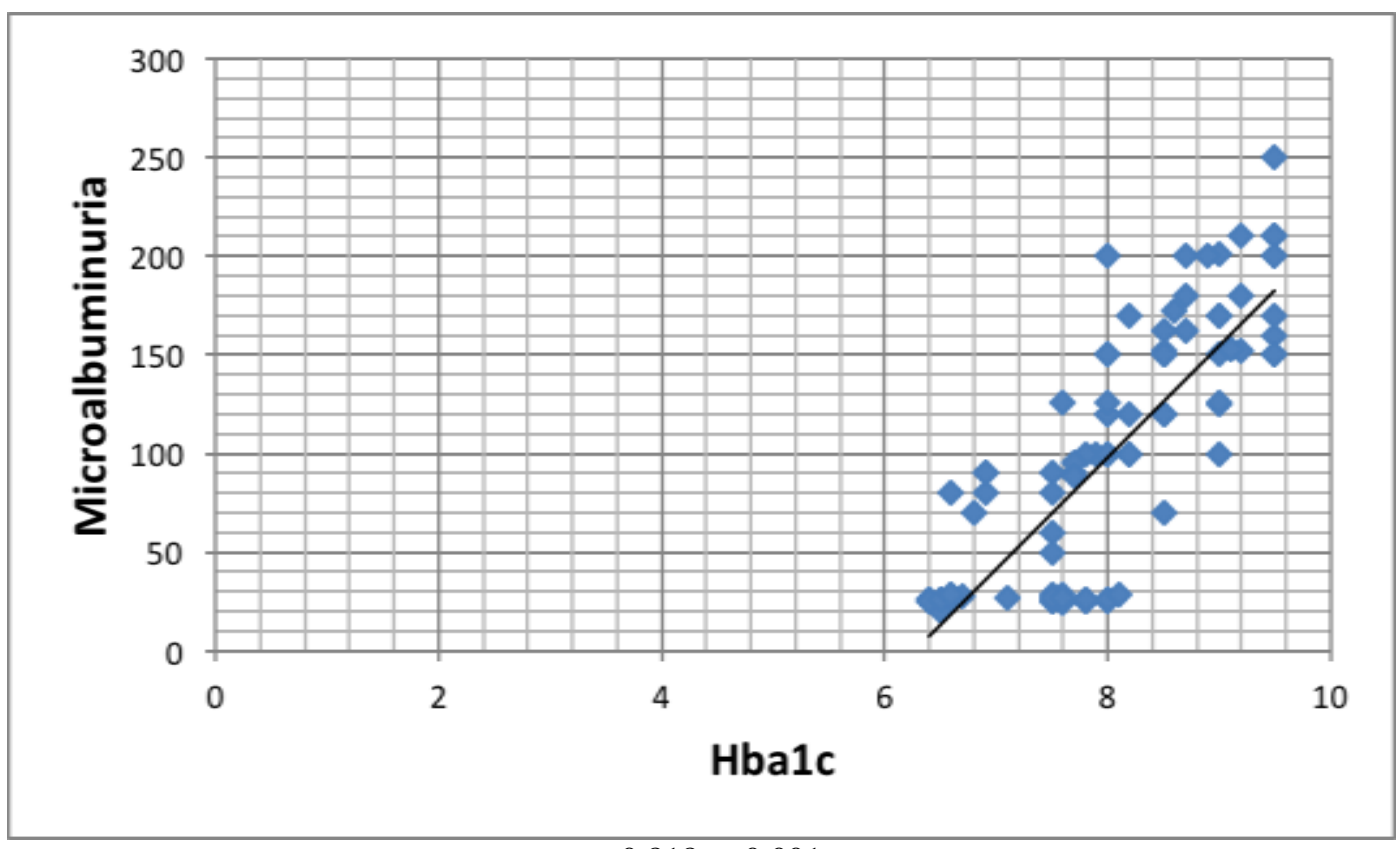

$\mathrm{r}=0.818, \mathrm{p}=0.001$

Fig 2:- Showing correlation coefficient between $\mathrm{HbA1C}$ and Microalbuminuria.

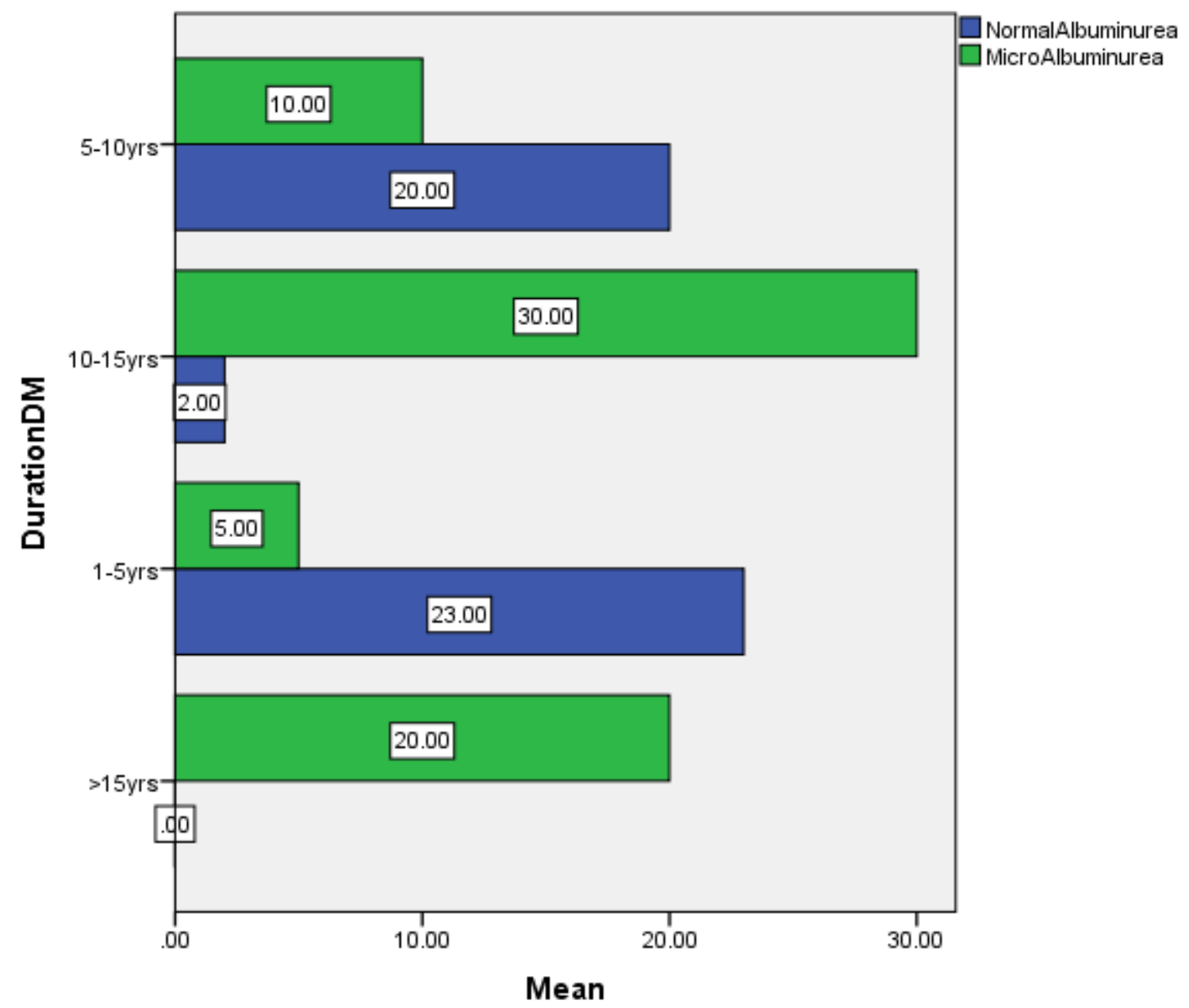

Fig 3:- Showing relation of duration of DM with albuminuria 


\section{Recommendations:-}

monitoring of glycemic status is considered a cornerstone of diabetes care and affects how physicians and patients adjust medical therapy as well as behavioral therapy (e.g., diet and exercise). Use of audio-visual media should be introduced both at Government level and at the level of N.G.Os. to propagate and educate the public about the short and long term complications of D.M.

\section{References:-}

1. Etienne G Krug.(2016):Trends in diabetes:sounding the alarm.Lancet.,387:1485-1486.

2. International Diabetes Federation, IDF Diabetes Atlas, International Diabetes Federation, Brussels, Belgium, $7^{\text {th }}$ edition,

3. 2015, http://www.diabetesatlas.org.

4. Tobe SW, Mc Farlane PA, and Naimark DM.(2002): Microalbuminuria in diabetes mellitus. CMAJ.,167:499503.

5. Tang SC, Chan GC, and Lai KN.(2016): Recent advances in managing and understanding diabetic nephropathy. F1000Res.,5: (Ekinci EI, Jerums G, Skene A,Crammer .

6. De Boer IH, Rue TC, Hall YN, et al.(2011): Temporal trends in the prevalence of diabetic kidney disease in the United States. JAMA., 305(24):2532-9.

7. Chowta NK, Pant P, Chowta MN.(2009):Microalbuminuria in diabetes mellitus: association with age, sex, weight and creatinine clearance. Indian J Nephrol.,19(2):53-56.

8. Sanjeev Kumar, Aneja GK, Trivedi A, Atam V, Shankhwar SN, Panwar A, and Pradeep Kumar. (2014):Correlation of Diabetic Nephropathy and HbA1C in newly diagnosed Type 2 Diabetic Patients of Western UP.International Journal of Scientific and Research.Publications.,12(4): 2250 -2254.

9. Tandon RK,Khare A,Gupta M,Nandwani S,Bansal R, and Sharma S.(2015):Relationship between glycosylated haemoglobin and risk of microalbuminuria in patients with Type 2 Diabetes Mellitus. Peoples Journal of Scientific Research.,1(8):14-18.

10. Muraliswaran P, Aparna G, Kanagavalli P, and Srikath S.(2013):Prevalence of microalbuminuria in relation to HbA1C among known type 2 diabetic patients in Puducherry population.RJPBCS.,4(1):458-62.

11. American Diabetes Association Diabetes Care 2014 Jan; 37(Supplement 1): S81S90. https://doi.org/10.2337/dc14-S081).

12. Ghai R, Verma ND, Goel A, Bhatnagar MK, Kapoor P, and Vashishta A.(1994) Microalbuminuria in non insulin dependent diabetes and essential hypertension:A marker of severe disease. J. Assoc. Physicians India., 42:771 -4.

13. Kanakamani J, Ammini AC, Gupta N, and Dwivedi SN.(2010):Prevalence of microalbuminuria among patients with type 2 diabetes mellitus. Diabetes Technology and Therapeutics., 12(2):161-166.

14. Maskari FA, Sadig ME, and Obineche E.(2008):Prevalence and determinants of microalbuminuria among diabetic patients in UAE.BMC Nephrology.,9:1. Available from:http://www.biomedcentral.com/14712369/9/1.

15. Nathan DM, Turgeon H, and Regan S.(2007): Diabetologia ., 50, 2239-2244 www.care.diabetes journals/contents/27/Suppl_1/s79-s8

16. Park SB, Kim SS, Kim IJ, et al . (2017):Variability in glycated albumin levels predicts the progression of diabetic nephropathy. J Diabetes Complications., 3.

17. Baig JA. (2017):Prevalence of microalbuminuria with relation to glycemic Research Gate.,Available from https://www.researchgate.net>publication.

18. Gupta M, andSingh JP.(2017):Correlation of microalbuminuria with glycosylated haemoglobin in patients of diabetes having nephropathy.Int J Adv Med., 4(3):805- 808.

19. Acharya K.Regmi S,Sapkota AS,Raut M, and Jha B.(2015):Microalbuminuria status in relation to glycated haemoglobin and duration of type 2 diabetes mellitus.ACCLM., 1(1):21-24.

20. Verghese A,Deepa R, Rema M, and Mohan V.(2001):Frequency of proteinuria in type 2 diabetes mellitus seen at a diabetic centre in south India. Post grad Med J., 77:399-402. 